\title{
Pilates and aerobic training improve levels of depression, anxiety and quality of life in overweight and obese individuals
}

\author{
O treinamento de Pilates e aeróbio melhoram os níveis de depressão, ansiedade e \\ qualidade de vida em indivíduos com sobrepeso e obesidade \\ Rodrigo Luiz Vancini', Angeles Bonal Rosell Rayes², Claudio Andre Barbosa de Lira ${ }^{1,3}$, Karine Jacon Sarro ${ }^{4}$, \\ Marilia Santos Andrade ${ }^{2}$
}

\begin{abstract}
Objective:To compare the effects of Pilates and walking on quality of life, depression, and anxiety levels. Methods: Sixty-three overweight/obese participants were randomly divided into: control $(n=20)$, walking $(n=21)$, and Pilates $(n=22)$ groups. Pilates and walking groups attended eight weeks of 60-minute exercise sessions three times per week. Quality of life, depression, and state- and trait-anxiety levels were evaluated before and after eight weeks of training. Results: Scores of quality of life, depression, and trait-anxiety improved in the Pilates and walking groups. State-anxiety levels improved only in the walking group. Conclusion: Pilates and walking positively impact quality of life, depression and anxiety. The Pilates method could be used as an alternative to improve mood disorders in overweight/obese individuals.
\end{abstract}

Keywords: exercise; complementary therapies; mental disorders; obesity.

\section{RESUMO}

Objetivo: Comparar os efeitos do treinamento com Pilates e caminhada sobre os níveis de qualidade de vida, depressão e ansiedade. Métodos: Sessenta e três participantes com sobrepeso/obesidade foram divididos aleatoriamente em grupos: Controle $(n=20)$, Caminhada $(n=21)$ e Pilates $(n=22)$. Os grupos Pilates e caminhada realizaram oito semanas de sessões de exercício de 60 minutos 3 vezes/semana. Os niveis de qualidade de vida, depressão e ansiedade traço e estado foram avaliados antes e após oito semanas de treinamento. Resultados: Os escores de qualidade de vida, depressão e ansiedade-traço melhoraram nos grupos Pilates e caminhada. Os níveis de ansiedade-estado melhoraram apenas no grupo caminhada. Conclusão: O Pilates e a caminhada impactam positivamente os níveis de qualidade de vida, depressão e ansiedade. 0 método Pilates pode ser usado como um método alternativo para distúrbios do humor em indivíduos com sobrepeso e obesidade.

Palavras-chave: exercício; terapias complementares; transtornos mentais; obesidade.

Obesity is associated with an increased risk of premature death and morbidities ${ }^{1}$. Physical inactivity, poor dietary habits, and urbanization have contributed to the obesity epidemic ${ }^{2}$. In addition, lower levels of quality of life and psychological disturbances have been associated with obesity ${ }^{1}$. Dankel et al. ${ }^{3}$ showed that the duration of the overweight/obesity condition and physical inactivity negatively impacts quality of life levels.

Different types of physical activity can be used as complementary treatments for individuals with obesity ${ }^{4,5}$. Barry et al. ${ }^{6}$ concluded that regardless of body mass index
(BMI), individuals with lower physical fitness levels had an increased risk of mortality over fit individuals.

Physical training is an effective strategy for improving quality of life and emotional health status ${ }^{6}$ and can diminish morbidities associated with obesity, such as depression and anxiety symptoms ${ }^{1,7.8}$. Sui et al. ${ }^{9}$ showed that physical fitness is inversely associated with depression symptoms.

In individuals with epilepsy, Vancini et al. ${ }^{10}$ demonstrated that low levels of maximal aerobic power impaired the mood state profile. Moreover, Becofsky et al. ${ }^{1}$ noted that a low level

${ }^{1}$ Universidade Federal do Espírito Santo, Centro de Educação Física e Desportos, Laboratório de Força e Condicionamento, Vitória ES, Brasil;

Universidade Federal de São Paulo, Departamento de Fisiologia, São Paulo SP, Brasil;

${ }^{3}$ Universidade Federal de Goiás, Faculdade de Educação Física e Dança, Laboratório da Avaliação do Movimento Humano, Setor de Fisiologia Humana e do Exercício, Goiânia GO, Brasil;

«Universidade Estadual de Campinas, Faculdade de Educação Física, Campinas SP, Brasil.

Correspondence: Marilia Santos Andrade; Departamento de Fisiologia da UNIFESP; Rua Botucatu, 862 / 5² andar; $04023-062$ São Paulo SP, Brasil;

E-mail:marilia1707@gmail.com

Support: FAPESP Financial support (grant number: 2013/08245-2).

Conflict of interest: There is no conflict of interest to declare.

Received 06 June 2017; Received in final form 26 August 2017; Accepted 05 September 2017. 
of fitness is more strongly associated with the onset of elevated depressive symptoms than several other measures of fatness, including BMI, waist circumference, and body fat percentage. To reduce the risk of developing depression, individuals should be encouraged to improve their physical fitness regardless of body fatness.

Aerobic activities, such as walking, have been suggested to improve aerobic physical fitness, quality of life, and mood disorders ${ }^{1,4}$. However, due to monotony and the difficulty of performing weight-bearing activities, adherence to these types of activities can be low, especially among obese individuals.

Alternative exercises, such as Pilates, could be suggested to overweight/obese individuals. Pilates is a form of body/mind training that requires different types of exercise (e.g., balance, endurance, strength, and flexibility) and attention to muscle control, posture, and breathing ${ }^{11,12}$. Niehues et al. ${ }^{13}$ noted that Pilates is a method of resistance training (based on isometric exercises) that is low-impact on the joints, which may be very attractive to overweight/obese individuals.

Despite several studies that have been conducted on the physical effects of Pilates training in obese individuals, conclusive results are not possible due to methodological concerns (e.g., the absence of randomized and control trials) ${ }^{14,15}$. To our knowledge, no studies have been conducted to verify the effects of Pilates training on quality of life, depression, and anxiety levels in overweight/obese individuals.

Therefore, our aim was to evaluate the effects of Pilates and traditional aerobic training (walking) on quality of life, anxiety, and depression measures among overweight/ obese participants.

\section{METHODS}

\section{Study participants}

Overweight/obese adults of both sexes (18-66 years) were enrolled in the study. Advertisements were posted on social networks and in a medical school to solicit volunteers.

The inclusion criteria were as follows: BMI (calculated by dividing body mass by height squared) $\geq 25 \mathrm{~kg} / \mathrm{m}^{2}$; at least six months without practising any kind of physical activity; and no history of disease (except obesity).

Initially, 118 participants were assessed for study eligibility by evaluating their health history and performing a medical examination. Forty-six $(n=46)$ individuals were excluded at this stage. The remaining 72 participants were divided into three groups: control [C $(n=20)$, female $(n=12,60 \%)$ and male $(\mathrm{n}=8,40 \%)]$, walking $[\mathrm{W}(\mathrm{n}=21)$, female $(\mathrm{n}=20$, $95.24 \%)$ and male $(\mathrm{n}=1,4.76 \%)]$, and Pilates $[\mathrm{P}(\mathrm{n}=22)$, female $(n=21,95.45 \%)$ and male $(n=1,4.55 \%)]$. However, nine participants withdrew from the study for personal reasons. After a clear explanation of the procedures, written consent was obtained. All of the experimental procedures were approved by the Human Research Ethics Committee of the University and conformed to the principles outlined in the Declaration of Helsinki.

The general characteristics of the individuals who participated $(\mathrm{n}=63)$ in the study are given in Table 1 .

Table 1. Demographic characteristics of the cohort components.

\begin{tabular}{|c|c|c|c|c|}
\hline Groups & $C$ & $W$ & $P$ & Statictical analveses \\
\hline Variables & $c$ & w & $r$ & statıstical analyses \\
\hline $\mathrm{BMI}\left(\mathrm{kg} / \mathrm{m}^{2}\right)$ & & & & \\
\hline Mean \pm SD & $31.9 \pm 4.0$ & $30.3 \pm 3.3$ & $31.1 \pm 4.0$ & $F(2,60)=0.95, p=0.39$ \\
\hline Median & 30.5 & 29.9 & 30.2 & \\
\hline Maximum & 40 & 37 & 41 & \\
\hline Minimum & 26 & 25 & 28 & \\
\hline Age (years) & & & & \\
\hline Mean \pm SD & $41.7 \pm 12.6$ & $42.4 \pm 7.0$ & $55.9 \pm 6.6^{*}$ & $F(2,60)=16.79, p<0.05$ \\
\hline Median & 45.5 & 42 & 56.5 & \\
\hline Maximum & 58 & 61 & 66 & \\
\hline Minimum & 18 & 33 & 40 & \\
\hline Body mass (kg & & & & \\
\hline Mean $\pm S D$ & $86.2 \pm 17.6$ & $79.0 \pm 10.6$ & $82.6 \pm 9.9$ & $F(2,60)=1.55, p=0.22$ \\
\hline Median & 78.9 & 81.1 & 80.6 & \\
\hline Maximum & 114 & 100 & 111 & \\
\hline Minimum & 62 & 58 & 68 & \\
\hline Height (cm) & & & & \\
\hline Mean \pm SD & $165.6 \pm 10.3$ & $161.3 \pm 7.6$ & $161.1 \pm 6.3$ & $F(2,60)=2.03, p=0.14$ \\
\hline Median & 163.5 & 161 & 160.0 & \\
\hline Maximum & 194 & 173 & 181 & \\
\hline Minimum & 154 & 141 & 148 & \\
\hline
\end{tabular}




\section{Study design}

A randomized (experimental groups - walking and Pilates), blinded and controlled study was carried out. Due to the nature of the interventions, it was not possible to blind the participants and coaches involved. However, the professionals involved with the tests and measurements were blinded and made aware of allocation details only after data analysis.

The study was organized in three phases: pre-intervention, treatment period, and post-intervention. In the three days before and after the treatment intervention, all of the participants underwent follow-up evaluations: anthropometry and a cardiopulmonary exercise test (CPET).

In the two days before and after the treatment intervention, all of the participants underwent the following follow-up evaluations: quality of life assessment using the 36-Item Short Form Health Survey (SF-36) questionnaire, depression assessment using the Beck Depression Inventory, and State-Trait Anxiety Inventory (IDATE). Lastly, the participants were given eight weeks of treatment intervention, three times per week, $60 \mathrm{~min} / \mathrm{session}$, on non-consecutive days.

When a participant missed three or fewer training sessions, these sessions were made up at the end of the program. However, when four or more sessions were missed, the participant was excluded from the study. As the $\mathrm{C}$ group did not follow an experimental protocol, for ethical reasons, the opportunity to participate in the $\mathrm{P}$ or $\mathrm{W}$ program was offered, according to the volunteer's interest, after the conclusion of the study.

\section{Cardiopulmonary exercise testing}

A CPET was performed to establish the ventilatory threshold (VT). The heart rate (HR) of the VT was used as the target during the walking sections. Before the CPET, the participants were provided with a standardized set of instructions explaining the tests. On completion of these preliminary procedures, each participant performed a treadmill test (Inbrasport, ATL, Porto Alegre, Brazil) to identify the VT. During the CPET, the participants were verbally encouraged to exercise for as long as possible. Respiratory gas samples were analyzed breath-to-breath using a gas analyzer (Quark, Cosmed, Italy). The HR was recorded using an HR monitor (Polar Electronics, FS1, Finland). The VT is a method of assessing aerobic fitness and was determined independently by two experienced investigators.

\section{Quality of life assessment}

Quality of life was evaluated with the SF-36, translated and validated for Brazilian Portuguese ${ }^{16,17}$. This questionnaire comprises 36 questions, grouped into eight domains: functioning capacity (1), limitations because of physical aspects (2), pain (3), general health (4), vitality (5), social functioning (6), limitations because emotional problems (7), and mental health (8). Subscale scores range from 0 to 100 , with 100 as the best, most positive life quality in that area and 0 is the worst.

\section{Depression and anxiety assessment}

The Brazilian version of the Beck Depression Inventory was used $^{18}$. There are 21 clinical symptoms of depression, and 10 additional items cover affective, behavioral, somatic, and interpersonal aspects of depression. Each item consists of a series of four statements scaled to indicate increasing depressive symptomatology. For this instrument, scores of 5 to 9 are considered normal, scores between 10 and 18 reflect mild-to-moderate depression, scores from 19 to 29 reflect moderate-to-severe depression, and scores from 30 to 63 reflect severe depression ${ }^{19}$.

Anxiety levels were evaluated using the State-Trait Anxiety Inventory. This is a self-reported assessment that includes separate measures of state- and trait-anxiety. It is a 40-item scale consisting of two 20 -item subscales (i.e., state and trait) to assess anxiety. The state-anxiety scale describes the individual's feelings at a particular time and under specific conditions, whereas the trait-anxiety scale describes the usual feelings of the individual. The scores for both the stateand trait-anxiety scales can vary from a minimum of 20 to a maximum of 80. A score higher than 30 indicates the presence of anxiety, a score of 31 to 49 indicates an intermediate level of anxiety and a score greater than or equal to 50 indicates a high degree of anxiety ${ }^{19}$.

\section{Training intervention \\ Pilates protocol}

All of the volunteers in the P group used HR monitors (Suunto, Ambit, Finland) to monitor HR during all training sessions. The sessions were performed at a Pilates studio in groups of five participants each and were led by qualified professionals who had been trained and experienced in the method for longer than seven years. The sessions were divided into the following three stages: Pre-Pilates (general warm-up of 10 minutes); Pilates training, which consisted of general conditioning (45 minutes for beginners and intermediates) with the original Pilates repertoire of mat exercises (mat Pilates) and used the following equipment: reformers, Cadillacs, chairs, magic circles, and dumbbells; and cool-down (respiratory exercises for five minutes). The repertoire of Pilates exercises was adapted and adjusted for obese/overweight individuals as required.

\section{Walking protocol}

An individual, supervised exercise program was developed for each volunteer based on the HR obtained at the VT in the cardiopulmonary test. This program consisted of performing eight weeks of moderate aerobic training in a park with a flat terrain, three times/week, with sessions of 60 minutes. Each one-hour session was divided into warm-up (10 minutes), walking (40 minutes) and cool-down (10 minutes). A walking activity performed at the VT intensity was selected to decrease orthopedic injuries in individuals with obesity. All of the participants used an HR monitor during all training sessions. 


\section{Statistical analyses}

The data were expressed as the mean \pm standard deviation. All of the variables were normally distributed according to the Kolmogorov-Smirnov test and exhibited homogeneous variability based on the Levene's test. The intervention effects were assessed using one-way analysis of variance and complemented with the Newman-Keuls post hoc test when the threshold of significance was reached. Statistical significance was set at an alpha value of 0.05 (Statistic software/version 6.0, 2002).

\section{RESULTS}

\section{Exercise session intensity}

The HR of exercise sessions (average of all sessions recorded in beats per minute - bpm) for the $\mathrm{W}$ group was $123.2 \pm 10.9 \mathrm{bpm}$. This HR represents approximately $70 \%$ of the HRmax ( $159.7 \pm 16.3 \mathrm{bpm})$ reached in the CPET. However, the HR reached for the P group was $86.3 \pm 6.1 \mathrm{bpm}$. This represents approximately $59 \%$ of the HRmax (145.6 $\pm 21.4 \mathrm{bpm})$ reached in the CPET. The HR during exercise training sessions was significantly higher $(29.9 \%)$ in the $\mathrm{W}$ group when compared to P group $(\mathrm{p}<0.0001)$.

\section{Quality of life}

In the quality of life assessment (SF-36, Table 2), the following results were observed for the different domains.

Regarding the "functioning capacity" and "general health" domains, there were no significant differences in the intra- (before vs. after training) or inter-group comparisons (C vs. W vs. P). For the "limitations because of physical aspects" domain, the $\mathrm{W}$ group $(54.7 \pm 42.3)$ showed a significantly lower score $(36.1 \%)$ before training compared with the C group (85.7 \pm 24.5$)$. The $\mathrm{W}$ group $(54.0 \pm 21.2)$ showed a significantly lower score $(29.5 \%)$ in the "pain" domain before training compared to the $\mathrm{C}$ group $(76.6 \pm 17.1)$. In addition, the $\mathrm{W}$ group exhibited significantly different pain scores between the before $(54.0 \pm 21.2) v s$. after $(72.8 \pm 17.1)$ training conditions, for an increase of 25.8\%. In the "vitality domain", the W group $(51.4 \pm 24.3)$ had significantly lower scores $(25.8 \%)$ before training when compared to the $\mathrm{C}$ group (69.3 \pm 15.3$)$. For the $\mathrm{W}$ group, the vitality score worsened significantly (by $7.8 \%$ ) when comparing the scores obtained before (51.4 \pm 24.3$)$ and after $(47.4 \pm 22.7)$ training. The P group $(54.0 \pm 21.2)$ showed a significantly lower score (22\%) before training when compared to the C group (69.3 \pm 15.3$)$. In addition, Pilates training (P group) significantly improved their vitality score by $28 \%$ ( $47.4 \pm 22.7$ before vs. $65.9 \pm 18.7$ after training). With respect to the "social functioning domain" the $\mathrm{W}$ group exhibited a significant improvement of $20.3 \%$ (70.2 \pm 27.2 before $v s .88 .1 \pm 16.0$ after training). Pilates training resulted in a significant improvement of $29.2 \%$ in the social functioning score after training $(57.7 \pm 28.9$ before $v$ s. after $81.5 \pm 24.9$ after training). As well, the P group (57.7 \pm 28.9$)$ had a significantly lower score (30.7\%) before training when compared to the $C$ group ( $83.3 \pm 25.7)$. For the domain "limitations because of emotional problems", the W group (49.2 \pm 46.7$)$ showed a significantly lower score (36.7\%) before training when compared to the $\mathrm{C}$ group (77.8 \pm 37.0 ). In addition, for the $\mathrm{W}$ group, the "limitations because of emotional problems" score was significantly increased (49.2 \pm 46.7 before $v$ s. $87.3 \pm 22.3$ after training). The P group (54.0 \pm 21.2$)$ showed a significantly lower score (14.8\%) before training when compared to the $C$ group $(46.0 \pm 40.0)$. Lastly, Pilates training led to a significant increase of $40.8 \%$ in this quality of life domain ( $46.0 \pm 40.0$ before $v s .77 .8 \pm 33.9$ after training). Regarding the "mental health domain", the $\mathrm{W}$ group (59.2 \pm 21.6$)$ had a significantly lower score $(23.2 \%)$ before training when compared to the $C$ group $(77.1 \pm 16.3)$. For the W group, the mental health score was significantly improved by $21.8 \%$ following training ( $59.2 \pm 21.6$ before $v s .75 .8 \pm 15.3$ after training). The P group (60.0 \pm 19.3$)$ had a significantly lower score (22.1\%) before training when compared to the $C$ group $(77.1 \pm 16.3)$. Lastly, Pilates training led to a significant improvement of $19 \%$ in the mental health score $(60.0 \pm 19.3$ before $v s .74 .1 \pm 22.4$ after training). All statistical data are shown in Table 2.

Using the Beck Inventory Depression assessment, it was observed that the W group (score: $18.7 \pm 6.9$ ) had a significantly higher score (36.3\%) before training compared to the C group $(11.9 \pm 6.9)$. For the $\mathrm{W}$ group, the levels of depression were significantly decreased, by $35.2 \%$ following training (18.7 \pm 6.9 before vs. $12.1 \pm 6.7$ after training). In the P group, training led to a significant decline (27.5\%) in depression levels ( $16.7 \pm 6.8$ before $v s .12 .1 \pm 6.4$ after training). All of the statistical data are shown in Table 2.

With respect to anxiety, the $\mathrm{W}$ group exhibited significantly diminished levels of trait-anxiety (15.1\%) following training ( $44.2 \pm 10.5$ before $v$ s. $37.5 \pm 7.7$ after training). In addition, the levels of trait-anxiety were decreased significantly $(14.1 \%)$ in the P group following training (45.3 \pm 10.3 before $v s .38 .9 \pm 10.8$ after training). Lastly, in the $\mathrm{W}$ group, we observed that the levels of state-anxiety significantly declined (18.5\%) after training ( $43.6 \pm 10.0$ before $v s .35 .5 \pm 7.9$ after training). All of the statistical data are shown in Table 2.

\section{DISCUSSION}

The purpose of the present study was to evaluate the impact of walking and Pilates on quality of life, depression, and anxiety levels in overweight/obese individuals. Our primary results were as follows. The $\mathrm{W}$ group showed improvements (pre- vs. post-training comparisons) in the quality of life domains of social functioning (20.3\%) and mental health (21.8\%). In addition, there were significant decreases in the levels of depression (35.2\%), trait-anxiety (15.1\%), and state-anxiety (18.5\%) in the pre- $v s$. post-training comparison. For the P group, improvements (pre- vs. post-training comparisons) were observed in the quality of life domains of 
Table 2. Quality of life, depression, and anxiety status in Control (C), Walking (W) and Pilates (P) groups before (B - week 0$)$ and $\operatorname{after}(\mathrm{A}$ - week 8$)$ the study protocol.

\begin{tabular}{|c|c|c|c|c|c|c|c|c|c|c|}
\hline \multirow{2}{*}{ Questionnaires } & \multicolumn{3}{|c|}{$C(n=20)$} & \multicolumn{3}{|c|}{$W(n=21)$} & \multicolumn{3}{|c|}{$P(n=22)$} & \multirow{2}{*}{$\begin{array}{l}\text { One way } \\
\text { ANOVA }\end{array}$} \\
\hline & $\mathrm{B}$ & A & $\Delta(\%)$ & $B$ & A & $\Delta(\%)$ & $B$ & A & $\Delta(\%)$ & \\
\hline SF-36 domains & Mean \pm SD & Mean \pm SD & & Mean \pm SD & Mean $\pm S D$ & & Mean \pm SD & Mean \pm SD & & \\
\hline 1 & $79.5 \pm 16.2$ & $84.0 \pm 13.4$ & $+10.4 \pm 32.6$ & $67.8 \pm 15.4$ & $80.7 \pm 13.5$ & $+24.6 \pm 36.3$ & $70.2 \pm 17.2$ & $75.5 \pm 17.0$ & $+12.5 \pm 31.2$ & $\begin{array}{c}F(2,60)=1.1114 \\
p=0.33576\end{array}$ \\
\hline Median & 80 & 85 & & 65 & 85 & & 70 & 75 & & \\
\hline Maximum & 100 & 100 & & 95 & 95 & & 95 & 95 & & \\
\hline Minimum & 30 & 50 & & 45 & 50 & & 20 & 40 & & \\
\hline 2 & $80.9 \pm 29.5$ & $83.3 \pm 29.9$ & $+11.2 \pm 79.8$ & $54.7 \pm 42.3$ & $85.7 \pm 24.5$ & $+21.7 \pm 37.2$ & $65.5 \pm 33.0$ & $76.2 \pm 34.9$ & $+6.0 \pm 55.7$ & $\begin{array}{c}F(2,50)=0.26498, p \\
=0.76829\end{array}$ \\
\hline Median & 100 & 100 & & 75 & 100 & & 75 & 100 & & \\
\hline Maximum & 100 & 100 & & 100 & 100 & & 100 & 100 & & \\
\hline Minimum & 0 & 0 & & 0 & 25 & & 0 & 0 & & \\
\hline 3 & $76.6 \pm 17.1$ & $74.7 \pm 20.1$ & $-1.8 \pm 19.4$ & $54.0 \pm 21.2$ & $72.8 \pm 17.1$ & $+83.4 \pm 196.2$ & $64.7 \pm 20.4$ & $75.0 \pm 23.7$ & $+30.1 \pm 63.8$ & $\begin{array}{c}F(2,60)=2.7172 \\
p=0.07419\end{array}$ \\
\hline Median & 72 & 74 & & 51 & 72 & & 62 & 84 & & \\
\hline Maximum & 100 & 100 & & 100 & 100 & & 100 & 100 & & \\
\hline Minimum & 41 & 31 & & 10 & 51 & & 22 & 10 & & \\
\hline 4 & $71.6 \pm 17.1$ & $77.1 \pm 11.9$ & $+12.1 \pm 24.1$ & $70.4 \pm 16.4$ & $78.3 \pm 17.8$ & $+14.5 \pm 27.3$ & $75.3 \pm 14.0$ & $80.5 \pm 9.9$ & $+10.4 \pm 23.6$ & $\begin{array}{c}F(2,60)=0.14169 \\
p=0.86818\end{array}$ \\
\hline Median & 77 & 72 & & 72 & 82 & & 77 & 82 & & \\
\hline Maximum & 100 & 100 & & 92 & 97 & & 97 & 92 & & \\
\hline Minimum & 35 & 57 & & 35 & 37 & & 40 & 57 & & \\
\hline 5 & $69.3 \pm 15.3$ & $69.3 \pm 16.1$ & $+1.9 \pm 19.9$ & $51.4 \pm 24.3$ & $70.5 \pm 19.9$ & $+162.4 \pm 399.1$ & $47.4 \pm 22.7$ & $65.9 \pm 18.7$ & $+105.2 \pm 176.4$ & $\begin{array}{c}F(2,60)=2.1869 \\
p=0.12114\end{array}$ \\
\hline Median & 75 & 100 & & 55 & 75 & & 50 & 70 & & \\
\hline Maximum & 90 & 30 & & 80 & 95 & & 80 & 95 & & \\
\hline Minimum & 25 & 100 & & 5 & 20 & & 5 & 15 & & \\
\hline 6 & $83.3 \pm 25.7$ & $88.1 \pm 17.4$ & $+5.3 \pm 28.4$ & $70.2 \pm 27.2$ & $88.1 \pm 16.0$ & $+48.7 \pm 77.5$ & $57.7 \pm 28.9$ & $81.5 \pm 24.9$ & $+73.6 \pm 164.4$ & $\begin{array}{c}F(2,58)=2.1366 \\
p=0.12725\end{array}$ \\
\hline Median & 100 & 100 & & 75 & 100 & & 62.5 & 87.5 & & \\
\hline Maximum & 100 & 100 & & 100 & 100 & & 100 & 100 & & \\
\hline Minimum & 0 & 37.5 & & 25 & 50 & & 0 & 0 & & \\
\hline 7 & $77.8 \pm 37.0$ & $90.5 \pm 26.1$ & $+12.9 \pm 52.2$ & $49.2 \pm 46.7$ & $87.3 \pm 22.3$ & $+15.3 \pm 63.3$ & $46.0 \pm 40.0$ & $77.8 \pm 33.9$ & $+58.9 \pm 93.6$ & $\begin{array}{c}F(2,42)=1.9978 \\
p=0.14832\end{array}$ \\
\hline Median & 100 & 100 & & 66 & 100 & & 33.3 & 100 & & \\
\hline Maximum & 100 & 100 & & 100 & 100 & & 100 & 100 & & \\
\hline Minimum & 0 & 0 & & 0 & 33.3 & & 0 & 0 & & \\
\hline 8 & $77.1 \pm 16.3$ & $79.2 \pm 14.2$ & $+4.5 \pm 15.1$ & $59.2 \pm 21.6$ & $75.8 \pm 15.3$ & $+43.7 \pm 54.1^{*}$ & $60.0 \pm 19.3$ & $74.1 \pm 22.4$ & $+31.1 \pm 46.9^{\#}$ & $\begin{array}{c}F(2,60)=4.7130 \\
p=0.01256\end{array}$ \\
\hline Median & 80 & 84 & & 60 & 80 & & 60 & 80 & & \\
\hline Maximum & 100 & 100 & & 92 & 96 & & 88 & 96 & & \\
\hline Minimum & 44 & 44 & & 24 & 52 & & 12 & 4 & & \\
\hline Beck & $11.9 \pm 6.9$ & $9.8 \pm 5.7$ & $-14.8 \pm 30.4$ & $18.7 \pm 6.9$ & $12.1 \pm 6.7$ & $-30.6 \pm 32.3$ & $16.7 \pm 6.8$ & $12.1 \pm 6.4$ & $-21.8 \pm 49.7$ & $\begin{array}{c}F(2,60)=0.88186, p \\
=0.41931\end{array}$ \\
\hline Median & 10 & 9 & & 19 & 10 & & 15 & 12 & & \\
\hline Maximum & 34 & 22 & & 35 & 34 & & 31 & 26 & & \\
\hline Minimum & 3 & 3 & & 6 & 6 & & 5 & 4 & & \\
\hline STAI Trait & $37.8 \pm 9.3$ & $35.7 \pm 7.7$ & $-3.7 \pm 15.7$ & $44.2 \pm 10.5$ & $37.5 \pm 7.7$ & $-12.9 \pm 15.9$ & $45.3 \pm 10.3$ & $38.9 \pm 10.8$ & $-14.0 \pm 13.4$ & $\begin{array}{c}F(2,60)=2.9466 \\
p=0.06016\end{array}$ \\
\hline Median & 35 & 36 & & 44 & 38 & & 43 & 36 & & \\
\hline Maximum & 55 & 55 & & 65 & 52 & & 78 & 67 & & \\
\hline Minimum & 20 & 20 & & 29 & 28 & & 34 & 26 & & \\
\hline STAI State & $38.0 \pm 8.4$ & $39.0 \pm 10.5$ & $+3.3 \pm 20.2$ & $43.6 \pm 10.0$ & $35.5 \pm 7.9$ & $-16.4 \pm 19.8^{*}$ & $41.0 \pm 9.8$ & $37.6 \pm 11.3$ & $-6.9 \pm 25.8$ & $\begin{array}{c}F(2,60)=4.1850 \\
p=0.01989\end{array}$ \\
\hline Median & 37 & 36 & & 41 & 34 & & 40 & 40 & & \\
\hline Maximum & 61 & 61 & & 70 & 52 & & 73 & 73 & & \\
\hline Minimum & 26 & 21 & & 32 & 22 & & 29 & 29 & & \\
\hline
\end{tabular}


vitality (28\%), social functioning $(29.2 \%)$ and mental health (19\%). In addition, there were significant decreases in the levels of depression (27.5\%) and trait-anxiety (14.1\%) when comparing pre- and post-training measures.

\section{Effects of physical exercise on quality of life}

The practice of physical activity has an important role in health promotion and is a key variable to increasing multidimensional aspects of quality of life ${ }^{4}$. On the other hand, better levels of quality of life are a motivator to augment physical activity practice. Physical activity can improve psychological variables such as cognitive function, social relationships, and mood status, which creates a positive health cycle. In this way, alternative practices (such as Pilates, which is a body/mind exercise), in addition to traditional activities (for example, walking), have been used in an attempt to improve the adherence levels of overweight/obese people in physical activity programs.

It is important to note that walking and Pilates programs significantly benefited health status and quality of life in overweight and/or obese individuals. In agreement with these results, several previous studies, in healthy and diseased groups, have demonstrated beneficial effects of physical activity on several quality of life and mental health parameters ${ }^{7,8,20,21,22}$.

Pilates exercise could be an alternative strategy for promoting health status and quality of life improvements in both nonclinical and clinical populations ${ }^{23,24,25,26,27}$. However, studies on the effects of Pilates training on quality of life and health status in overweight and/or obese individuals are scarce.

\section{Studies on quality of life in health samples}

Longitudinal and cross-sectional studies have shown a positive association between physical activity (level and behavior) and a better mental health and perception of quality of life.

Cruz-Ferreira et al. ${ }^{28}$ demonstrated that mat Pilates training improved the perception of health status in healthy women. Vieira et al. ${ }^{26}$ evaluated the effects of Pilates training on SF-36 quality of life components in healthy female and male individuals (beginners, experienced, and expractitioners) and found that physical function, general health, and mental health were all improved. Finally, García-Soidán et al. ${ }^{25}$ showed that 12 weeks of Pilates training significantly improved physical and emotional quality of life domains in middle-aged individuals. Therefore, our results are in agreement with the literature.

\section{Studies on quality of life in clinical samples}

In healthy people and those with chronic diseases, a positive association between physical activity levels and quality of life could provide motivation to become more physically active, more so than the remote perspective of decreasing and mitigating the risk and prognosis of diseases. This premise could be applied to overweight/obese people ${ }^{3}$ despite of the scarcity of studies on the effects of Pilates in this population.
Kofotolis et al. ${ }^{29}$ studied the impact of eight weeks of Pilates training and trunk-strengthening exercises on quality of life in women with chronic low back pain. These authors demonstrated that the Pilates group had a greater improvement in self-reported quality of life compared to the trunkstrengthening exercise group. It is important to point out that Pilates could be a complementary method of training with the potential to improve the functional capacity of obese individuals. ${ }^{13}$ It is possible that this benefit is related to improved body composition and a reduction in both obesity and BMI after Pilates training ${ }^{14,15,30}$. In agreement with the literature, we also observed improvements in the quality of life of overweight and obese individuals after Pilates training.

\section{Effects of physical exercise on anxiety and depression}

Emotional malfunction seems to inhibit the positive perception of the physical benefits to the quality of life of people with psychological disorders and chronic diseases ${ }^{5}$. In this sense, the presence of depression and anxiety may have a negative effect on several dimensions of quality of life, including physical functioning, which may negatively impact quality of life levels. This could be even more present in overweight and obese individuals because of the locomotion and weight-bearing difficulties ${ }^{1}$. Although there are many studies on the practice of physical activity in anxiety and depression levels (acute and chronic), the literature on the effects of Pilates is scarce, particularly in overweight/obese individuals. Ekici et al. ${ }^{23}$ demonstrated that four weeks of Pilates training in women with fibromyalgia improved state- and trait-anxiety levels. It is important to note that we observed improvements in the levels of depression and anxiety after Pilates training in overweight/obese individuals.

In conclusion, different types of physical activity may contribute to improvement in quality of life. In addition, mental and emotional benefits may be the trigger motivator factors for people's perception of physical activity programs, especially for overweight/obese people. We found that eight weeks (three sessions/week) of Pilates and aerobic training, with monitored and progressively-adjusted intensity, positively impacted quality of life, depression and anxiety. Similar to traditional exercises, such as walking, which is routinely prescribed for overweight/obese individuals, Pilates training may be used as an effective alternative approach to improve overall patient health, self-esteem, emotional and psychological state, mood, and motivation. In this way, Pilates could be an important component in a strategy to achieve the difficult task of losing weight.

\section{Practical applications}

Our study was a randomized, blinded, and controlled trial showing that, similar to traditional activities (e.g., walking), Pilates training can be used as an alternative strategy to improve quality of life, depression, and anxiety in overweight/obese individuals. The strengths of our study were that our experimental design consisted of three randomly-allocated groups (control, 
walk, and Pilates). Moreover, few participants left the study (nine out of 70) during the course of training. A low loss of participation is an advantage in longitudinal studies. Lastly, the intensity of the training program was controlled throughout the experimental protocol for the walking and Pilates groups. These adjustments were made in each session when necessary to achieve an exercise overload that caused the desired adaptations.

\section{Limitations}

Every questionnaire study has subjective questions that can lead to loss in accuracy and reliability. Another factor to note is that the participants began from high base values for most of the analyzed variables. This fact may explain in part why we did not observe significant differences between the different time points and groups analyzed. Other limitations include that the age range of the participants was broad (18-66 years), all groups included both women and men (but disproportionately between the control and exercised groups), and the mean age for the Pilates group was significantly higher than for the control and walking groups.

\section{Acknowledgements}

We would like to thank FAPESP for the financial support (grant number: 2013/08245-2) and all of the subjects who volunteered their time to participate in the study, the Olympic Training and Research Center (Centro Olímpico de Treinamento e Pesquisa - COTP, São Paulo, Brazil), and the CGPAPilates Studio (São Paulo, Brazil).

\section{References}

1. Becofsky KM, Sui X, Lee DC, Wilcox S, Zhang J, Blair SN. A prospective study of fitness, fatness, and depressive symptoms. Am J Epidemiol. 2015;181(5):311-20. https://doi.org/10.1093/aje/kwu330

2. Ross SE, Flynn JI, Pate RR. What is really causing the obesity epidemic? A review of reviews in children and adults. J Sports Sci. 2016;34(12):1148-53. https://doi.org/10.1080/02640414.2015.1093650

3. Dankel SJ, Loenneke JP, Loprinzi PD. The WATCH (Weight Activity and Time Contributes to Health) paradigm and quality of life: the impact of overweight/obesity duration on the association between physical activity and health-related quality of life. Int J Clin Pract. 2016;70(5):409-15. https://doi.org/10.1111/ijcp.12797

4. Pedersen BK, Saltin B. Exercise as medicine - evidence for prescribing exercise as therapy in 26 different chronic diseases. Scand J Med Sci Sports. 2015;3:1-72. https://doi.org/10.1111/sms.1258

5. Elbelt U, Ahnis A, Riedl A, Burkert S, Schuetz T, Ordemann J et al. Associations of physical activity with depressiveness and coping in subjects with high-grade obesity aiming at bariatric surgery: a cross-sectional study. Biopsychosoc Med. 2015;9(1):16. https://doi.org/10.1186/s13030-015-0042-4

6. Barry VW, Baruth M, Beets MW, Durstine JL, Liu J, Blair SN. Fitness vs. fatness on all-cause mortality: a meta-analysis. Prog Cardiovasc Dis. 2014;56(4):382-90. https://doi.org/10.1016/j.pcad.2013.09.002

7. Galper DI, Trivedi MH, Barlow CE, Dunn AL, Kampert JB. Inverse association between physical inactivity and mental health in men and women. Med Sci Sports Exerc. 2006;38(1):173-8. https://doi.org/10.1249/01.mss.0000180883.32116.28

8. Pasco JA, Williams LJ, Jacka FN, Henry MJ, Coulson CE, Brennan SL et al. Habitual physical activity and the risk for depressive and anxiety disorders among older men and women. Int Psychogeriatr. 2011;23(2):292-8. https://doi.org/10.1017/S1041610210001833

9. Sui X, Laditka JN, Church TS, Hardin JW, Chase N, Davis Ket al. Prospective study of cardiorespiratory fitness and depressive symptoms in women and men. J Psychiatr Res. 2009;43(5):546-52. https://doi.org/10.1016/j.jpsychires.2008.08.002

10. Vancini RL, Lira CA, Andrade MS, Lima C, Arida RM. Low levels of maximal aerobic power impair the profile of mood state in individuals with temporal lobe epilepsy. Arq Neuropsiquiatr. 2015;73(1):7-11. https://doi.org/10.1590/0004-282X20140188PMID:25608120

11. Latey P. Updating the principles of the Pilates method part 2.J Bodyw Mov Ther. 2002;6:94-101. https://doi.org/10.1054/jbmt.2002.0289
12. Küçükçakır N, Altan L, Korkmaz N. Effects of Pilates exercises on pain, functional status and quality of life in women with postmenopausal osteoporosis. J Bodyw Mov Ther. 2013;17(2):204-11. https://doi.org/10.1016/j.jbmt.2012.07.003

13. Niehues JR, Gonzáles I, Lemos RR, Haas P. Pilates method for lung function and functional capacity in obese adults. Altern Ther Health Med. 2015;21(5):73-80.

14. Jago R, Jonker ML, Missaghian M, Baranowski T. Effect of 4 weeks of Pilates on the body composition of young girls. Prev Med. 2006;42(3):177-80. https://doi.org/10.1016/j.ypmed.2005.11.010

15. Cakmakçi O. The effect of 8 week pilates exercise on body composition in obese women. Coll Antropol. 2011;35(4):1045-50. https://doi.org/10.0000/PMID22397236

16. Ware JE Jr, Sherbourne CD. The MOS 36-item short-form health survey (SF-36):I. Conceptual framework and item selection. Med Care. 1992;30(6):473-83.https://doi.org/10.1097/00005650-199206000-00002

17. Ciconelli RM, Ferraz MB, Santos W, Meinão I, Quaresma MR. Brazilian-Portuguese version of SF-36. A reliable and valid quality of life outcome measure. Rev Bras Reumatol. 1999;39(3):143-50.

18. Beck AT, Steer RA. Beck Depression Inventory manual. San Antonio, TX: Psychological Corporation;1993

19. Gorenstein C, Andrade L. Validation of a Portuguese version of the Beck Depression Inventory and the State-Trait Anxiety Inventory in Brazilian subjects. Braz J Med Biol Res. 1996;29(4):453-7.

20. Carek PJ, Laibstain SE, Carek SM. Exercise for the treatment of depression and anxiety. Int J Psychiatry Med. 2011;41(1):15-28. https://doi.org/10.2190/PM.41.1.c

21. Kell RT, Bell G, Quinney A. Musculoskeletal fitness, health outcomes and quality of life. Sports Med. 2001;31(12):863-73. https://doi.org/10.2165/00007256-200131120-00003

22. Paffenbarger RS Jr, Lee IM, Leung R. Physical activity and personal characteristics associated with depression and suicide in American college men. Acta Psychiatr Scand Suppl. 1994;377:16-22. https://doi.org/10.1111/j.1600-0447.1994.tb05796.x

23. Ekici G, Unal E, Akbayrak T,Vardar-Yagli N, YakutY, Karabulut E. Effects of active/passive interventions on pain, anxiety, and quality of life in women with fibromyalgia: randomized controlled pilot trial. Women Health. 2017;57(1):88-107.https://doi.org/10.1080/03630242.2016.1153017

24. Mazzarino M, Kerr D, Wajswelner H, Morris ME. Pilates method for women's health: systematic review of randomized controlled trials. Arch Phys Med Rehabil. 2015;96(12):2231-42. https://doi.org/10.1016/j.apmr.2015.04.005 
25. García-Soidán JL, Giraldez VA, Cachón Zagalaz J, Lara-Sánchez AJ. Does pilates exercise increase physical activity, quality of life, latency, and sleep quantity in middle-aged people? Percept Mot Skills. 2014;119(3):838-50. https://doi.org/10.2466/29.25.PMS.119c30z9

26. Vieira FT, Faria LM, Wittmann JI, Teixeira W, Nogueira LA. The influence of Pilates method in quality of life of practitioners. J Bodyw Mov Ther. 2013;17(4):483-7. https://doi.org/10.1016/j.jbmt.2013.03.006

27. Leopoldino AA, Avelar NC, Passos GB Jr, Santana NÁ Jr, Teixeira VP Jr, Lima VP et al. Effect of Pilates on sleep quality and quality of life of sedentary population. J Bodyw Mov Ther. 2013;17(1):5-10. https://doi.org/10.1016/j.jbmt.2012.10.001
28. Cruz-Ferreira A, Fernandes J, Gomes D, Bernardo LM, Kirkcaldy BD, Barbosa TM et al. Effects of Pilates-based exercise on life satisfaction, physical self-concept and health status in adult women. Women Health. 2011;51(3):240-55. https://doi.org/10.1080/03630242.2011.563417

29. Kofotolis N, Kellis E, Vlachopoulos SP, Gouitas I, Theodorakis Y. Effects of Pilates and trunk strengthening exercises on health-related quality of life in women with chronic low back pain.J Back Musculoskeletal Rehabil. 2016;29(4):649-59. https://doi.org/10.3233/BMR-160665

30. Hagner-Derengowska M, Kałużny K, Kochański B, Hagner W, Borkowska A, Czamara A et al. Effects of Nordic Walking and Pilates exercise programs on blood glucose and lipid profile in overweight and obese postmenopausal women in an experimental, nonrandomized, open-label, prospective controlled trial. Menopause. 2015;22(11):1215-23. https://doi.org/10.1097/GME.0000000000000446 